\title{
Utilización de la Jeringa de Karman en Ginecología
}

\author{
Dr. Jorge Villareal Mejía \\ Dra. Rosalina Forero de Calderon
Unidad de Orientación y Asistencia Materna Bogotá, Colombia

Trabajo presentado al XIV Congreso Colombiano de Obstetricia y Ginecología. Cartagena. Diciembre 1981.

\section{RESUMEN}

La combinación de una cánula flexible de plástico transparente con una jeringa de succión, también de plástico, constituye lo que generalmente se conoce hoy en todo el mundo como la jeringa de Karman, que en Colombia no ha tenido aun la difusión y el conocimiento que su gran utilidad merece por parte de los especialistas en el campo de la obstetricia y la ginecología.

La introducción, hace poco más de una década, de un sencillo sistema de succión endouterina en el instrumental del ginecólogo, representa un avance que merece destacarse.

Este trabajo pretende dar a conocer en forma amplia este novedoso, simple y útil sistema de succión, de gran valor como ayuda diagnóstica y terapéutica para el ginecólogo moderno, por medio de la presentación de las características del equipo, la técnica y los hallazgos en 236 casos en los cuales fue utilizado, con particular eficacia, en la UNIDAD DE ORIENTACION, Y ASISTENCIA MATERNA de Bogotá.
La historia de la instrumentación endouterina se remonta a los orígenes mismos del ejercicio organizado de la medicina, pues existe evidencia arqueológica en las ruinas de Pompeya, de hallazgos de instrumentos cuyo objetivo era claramente la evacuación del contenido de la cavidad uterina.

La cureta, originalmente diseñada para limpiar las heridas quirúrgicas, fue inventada en 1723 por Jarengeot en Francia, pero fue Recamier, que también recibe el crédito por la aplicación del espéculo en ginecología, quien más tarde puso en práctica el curetaje o raspado endouterino. Más tarde, Simpson en Inglaterra, Simms en los Estados Unidos y Hegar en Alemania (1874), establecieron formalmente la práctica y el término de la dilatación y el curetaje, ampliamente aceptados hoy en el mundo entero.

Aproximadamente por la misma época, se inició la práctica de la succión endouterina, cuando Simpson primero (1), y Bykov (2) años más tarde, comenzaron a utilizar diversos sistemas de 
vacío acoplados a sondas vesicales con múltiples orificios, con el objeto de introducir substancias irritantes en la cavidad uterina, o de succionar el contenido de la misma.

Luego de varias décadas en el olvido, la técnica de aspiración endouterina cc-menzó nuevamente a popularizarse hacia 1958, a raíz de los trabajos de Wu y Wu (3) y Liu (4) en China, seguidos pocos años después, por la exitosa experiencia de Beric (5) en Yugoeslavia.

En 1961 se produce un cambio substancial en la tecnología de la aspiración uterina con la introducción, por parte de Harvey Karman, psicólogo y no médico, de una sencilla modificación a los tubos de succión previamente popularizados por Kerslake y Casey (6) en Inglaterra. La ingeniosa modificación propuesta por Karman consistió en utilizar tubos delgados de polietileno con dos aberturas en lugar de una sola, localizadas cerca de la punta del tubo, lo cual permitía que éste se doblase fácilmente al contacto con la pared uterina, evitándose así la perforación y la interrupción de la succión, al bloquearse el orificio único de los tubos utilizados por sus antecesores.

Las modificaciones introducidas por Karman (7) en la técnica de succión endouterina, fueron rápidamente difundidas en todo el mundo. Hoy en día, muchos centros médicos en diversos países, documentan, a través de innumerables casos, la eficacia e inocuidad de este método de evacuación uterina durante el primer trimestre de embarazo.

En 1971 se inició, además, la utilización de una jeringa de plástico con capacidad de 50 cc., la cual, acoplada con la cánula flexible diseñada por Karman, se ha venido conociendo con el nombre de Jeringa de Karman, y cuya utilización en el campo de la ginecología constituye el objeto de esta presentación;

\section{Aspectos técnicos del equipo de mini- succión}

El equipo de mini-succión uterina en referencia, consta en realidad de dos elementos básicos: cánulas y jeringa.

Las cánulas está fabricadas en polietileno flexible $y$ t tnsparente, $y$ tienen una punta redondeada que puede insertarse en la cavidad uterina con o sin dilatación del canal endocervical, de acuerdo con la paridad de la paciente. Su paso por dicho canal se hace muy fácil, aun desde la iniciación del flujo menstrual.

La cánula tiene $20 \mathrm{~cm}$. de longitud y viene en calibres diversos, con diámetro externo de 4 - 5 - 6 milímetros, lo cual permite su utilización sin dilatación previa, sobre todo en las pacientes multíparas.

La presencia de dos aberturas de aproximadamente $10 \mathrm{~cm}$. de longitud en lados opuestos de la cánula, permite que la punta se doble cuando encuentra resistencia, evitando así la perforación de la pared uterina. Los bordes de la abertura actúan no sólo como instrumento de succión, sino también como curetas, cuando se produce el adosamiento de esos bordes a la cavidad uterina, una vez que se produce el vacio en la jeringa y en la luz de la cánula.

El mecanismo de succión reside en lajeringa de plástico no flexible y transparente, con capacidad de 50 cc., completamente desarmable, que alcanza a ejer. cer una presión negativa hasta de $60 \mathrm{~cm}$. de mercurio.

Las características anotadas hacen de la cánula de Karman un instrumento que combina idealmente las funciones de dilatación, histerometría, aspiración y raspado uterino y cuenta, además, con ventajas adicionales como su bajo costo, la simplicidad de su esterilización y mantenimiento y su durabilidad. 
Una vez utilizado, el equipo debe ser desarmado y lavado con agua corriente, usando un jabón suave, únicamente para remover coágulos o partículas de tejido que no sea posible quitar con agua tibia o fría.

El émbolo de la jeringa debe ser lubricado cada dos o tres utilizaciones con grasa especial de silicona, fácilmente adquirible. Rearmada la jeringa, no necesita ser esterilizada, pues sus componentes nunca entran en contacto con la cavidad uterina.

Una vez que las cánulas han sido lavadas cuidadosamente, deben ser esterilizadas en Benzal (Cloruro de benzalconium $1=750$ por un mínimo de 40 minutos). Se puede utilizar, también, las soluciones yodadas o mejor aún, la esterilización por gas.

En nuestra experiencia, hemos utilizado con todo éxito el Benzal, cuyo poder antiséptico ha sido comprobado por medio de cultivos periódicos, todos ellos negativos, y por las tasas extraordinariamente bajas de infección post-succión, en el rango de una por mil durante los últimos cuatro años.

Las cánulas, supuestamente desechables, tienen una gran resistencia y pueden ser utilizadas un buen número de veces. Igualmente, las jeringas tienen amplia durabilidad, lo cual contribuye al muy bajo costo de adquisición y mantenimiento del equipo.

\section{Utilización de la Jeringa en Ginecología}

$\mathrm{Si}$ bien en el campo obstétrico la succión uterina tiene ya una larga historia, en el campo estrictamente ginecológico fue Emil Novak (8) quien en 1935 por primera vez promovió el uso de esta tecnología con fines esencialmente diagnósticos.

La cánula o cureta de Novak, instru mento metálico y rígido, ha sido superada por las cánulas de Karman, cuyas indicaciones son prácticamente las mismas. El objetivo principal del uso de dichas cánulas es la obtención de fragmentos de tejido endometrial para estudio histopatológico relacionado con el diagnóstico y tratamiento de la mujer infértil y el diagnóstico de procesos neoplasicos o disfuncionales, morfológicamente evidentes en el endometrio.

El equipo de mini-succión de Karman incorpora ventajas adicionales que vale la pena destacar, como son, por ejemplo, su posible utilización para efectuar la succión y evacuación de la cavidad uterina con fines terapéuticos, en el caso de hemorragias uterinas disfuncionales o por retención de restos ovulares.

Gracias a las características del equipo aquí descrito, a las ventajas anotadas debe agregarse el hecho de que la succión endouterina se convierte en un procedimiento ambulatorio y de consultorio, que no requiere hospitalización de la paciente.

\section{Técnica de utilización de la Jeringa de Karman en Ginecología}

Al igual que cualquier procedimiente quirúrgico realizado en la pelvis femenina, la succión de la cavidad endometrial debe ir precedida de un cuidadoso estudio de la historia clínica, y de un examen ginecológico que garantice la correcta valoración de las características anatómicas de la paciente.

De particular importancia será la ıdentificación de tamaño posición y movilidad del cuerpo uterino, de su situación en la línea media o de la existencia de laterodesviaciones. Las caracter ísticas del cuello uterino son también de gran importancia, en lo que atañe a su tamaño, protrusión dentro de la cúpula vaginal, diámetro estimado del canal endocervical, su longitud con relación al fondo o cuerpo uterino, y el grado mayor o menor de estenosis del orificio cervical externo. 
Como es de rutina en el examen pélvico, se deberá aprovechar la oportunidad para la toma de citología vaginal y muestras de flujo cuando estén indicadas.

La limpieza y desinfección de la vagina puede hacerse con torundas de gasa estériles, empapadas en Benzal. Aunque algunos autores afirman que el paso de las cánulas puede hacerse sin necesidad de utilizar tenaculum cervical, nuestra experiencia ha mostrado que la aplicación del tenáculum es generalmente indolora y permite bascular el cuerpo uterino, haciendo que el eje de la cavidad coincida con el del canal cervical y vaginal.

Una vez aplicado el tenáculum, se procede a la introducción de la cánula escogida para la succión endouterina, de 4 - 5 - 6 milímetros, según la capacidad estimada del canal endocervical, y teniendo en cuenta la paridad y el objetivo específico del procedimiento, sea éste diagnóstico o terapéutico. En este último caso, se debe tratar de utilizar cánulas de mayor diámetro.

En las pacientes nulíparas, casi siempre es necesaria la dilatación cervical para utilizar cánulas de $6 \mathrm{~mm}$ de diámetro o más. Esta se realiza empleando los dilatadores plásticos, ligeramente flexibles de Pratts o de Denisson, cuyo diámetro aumenta gradualmente, evitando así el dolor que usualmente acompaña esta parte del procedimiento.

Una vez terminada la dilatación, alcanzando un diámetro igual o un milímetro mayor que el de la cánula que se desea utilizar, se procede a la introducción de la cánula. En nuestra práctica hemos encontrado más seguro acoplar la cánula seleccionada a la jeringa de Karman antes de introducir aquella en la cavidad uterina, revisando que quede bien ajustada y observando la precaución de evitar que las 4/5 partes distales sean contaminadas.

EI manejo de cánulas y jeringas debe hacerse con las manos muy limpias pero sin guantes, pues éstos disminuyen en grado significativo la sensación táctil muy delicada que permite al ginecólogo percibir en todo detalle el curso que la punta de la cánula ha seguido, y determinar oportunamente el momento en que se completa la succión endouterina.

Una vez pasado el orificio cervical interno, se avanza la punta de la cánula hasta el fondo de la cavidad uterina. En ese punto, se abre la válvula localizada en el extremo distal de la jeringa, permitiendo que se ejerza el vacío previamente alcanzado mediante la extracción total del émbolo. En este momento, las paredes de la cavidad endometrial, que es de por sí virtual más que real, se adosan fuertemente entre sí, evitando que el vacío se pierda. Simultáneamente, las aberturas en la punta de la cánula también se acercan a la superficie endometrial. Cuando esto ocurre, el ginecólogo debe rotar jeringa y cánula 180 grados hacia la derecha e izquierda. Dicho movimiento circular se complementa con otro de traslación hacia afuera y hacia adentro de la cavidad uterina, llegando hasta el orificio interno pero sin traspasarlo, para evitar que se pierda el vacío dentro de la cavidad.

Si se llegase a perder la presión negativa o de succión por extracción involuntaria de la punta de la cánula, o en caso de cuellos muy dilatados o desgarrados, se podrá desconectar la cánula de la jeringa para volver a producir el vacío antes de reconectarla nuevamente, o sacar cuidadosamente cánula $y$ jeringa $y$, por fuera de la vagina, llevar a cabo la misma operación con mayor comodidad $y$ menos riesgos.

La transparencia de al cánula permite al ginecólogo ver el tipo y cantidad de 
tejido que ha obtenido de la cavidad uterina. Lo anterior, sumado a la sensación auditiva y táctil de pared uterina rugosa, pone en evidencia que la cavidad está desocupada y, por lo tanto, el procedimiento ha terminado. Un indicador adicional será la presencia de burbujas visualizadas a través de la cánula.

\section{Casu ística}

Darante los últimos cuatro años, se ha venido utilizando el equipo de succión endouterina de Karman en forma regular en la UNIDAD DE ORIENTACION $Y$ ASISTENCIA MATERNA, centro especializado de diagnóstico y tratamiento ambulatorio en la ciudad de Bogotá.

A continuación, se presentan en forma resumida los datos más importantes relacionados con 236 pacientes a quienes se les sometió al método de succión descrito, con fines diagnósticos y terapéuticos en este centro asistencial:

TABLA No. 1

\begin{tabular}{lr}
\hline \multicolumn{3}{c}{ EDAD } \\
\hline Grupo & \multicolumn{1}{c}{$\%$} \\
\hline $15-19$ & 8.5 \\
$19-24$ & 21.3 \\
$25-29$ & 27.2 \\
$30-34$ & 23.0 \\
$35-39$ & 11.0 \\
$40+$ & 9.0 \\
\hline
\end{tabular}

Tal como se comprobó por medio del examen histopatológico del tejido obtenido, ninguna de las pacientes en este estudio estaba embarazada, aunque el $62.7 \%$ presentara algún grado de retraso,
TABLA No. 2

PARIDAD

\begin{tabular}{cc}
\hline & $\%$ \\
\hline 0 & 39.5 \\
1 & 17.8 \\
2 & 16.9 \\
3 & 8.4 \\
4 & 6.9 \\
5 & 5.0 \\
$6+$ & 5.5 \\
\hline & $100 \%$ \\
\hline
\end{tabular}

TABLA No. 3

SEMANAS DESDE LA ULTIMA MENSTRUACION NORMAL

\begin{tabular}{rrr}
\hline & & $\%$ \\
\hline 5 & 0 menos & 37.3 \\
7 & -6 & 24.1 \\
9 & -10 & 17.8 \\
11 & -12 & 13.1 \\
$13+$ & 5.1 \\
\hline
\end{tabular}

menstrual y varias de ellas tuvieran restos ovulares retenidos.

La gran mayoría de las pacientes consultaron por trastornos del ciclo menstrual o sangrado genital, y $20.4 \%$ por esterilidad. Solamente $13 \%$ temían estar embarazadas, lo cual fue descartado clínicamente por medio de examen de laboratorio. El contraste de esta cifra con el $62.7 \%$ de pacientes con amenorrea que aparece en la tabla anterior, se explica por un gran número de amenorreas de lactancia y, probablemen- 
te, por el error tan frecuente al recordar la fecha exacta de la última menstruación.

Un buen número de las amenorreas de más de 6 semanas puede haber sido causado por la administración de drogas para inducir la menstruación atrasada, registrada en $35.5 \%$ de las pacientes estudiadas. Esta práctica, muy difundida inclusive dentro del cuerpo médico, contribuye a la realización de maniobras abortivas, no sólo altamente peligrosas sino, además, innecesarias.

TABLA No. 4

HALLAZGOS DEL EXAMEN PELVICO

Negativos $\frac{\%}{53.4}$

Compatibles con Dx. de Aborto incompleto

Utero aumentado de tamaño

29.2

Otros

$\frac{7.6}{100 \%}$

El hallazgo de útero aumentado de tamaño registrado en $29.2 \%$ de las historias clínicas, se interpretó como un hecho anatómico posiblemente relacionado con la multiparidad y no con sospecha de embarazo. Además, en el $3.8 \%$ de las pacientes se encontró alguna patología cervical.

En esta época de tan amplia difusión de los métodos anticonceptivos, y en un grupo poblacional en plena actividad sexual como el representado por este estudio, parece importante anotar que $38.5 \%$ no habían utilizado recientemente ningún método y sólo 31 de cada cien habían utilizado métodos modernos (orales, DIU, inyectables o esterilización).
Todos los casos en este estudio se trataron utilizando como mecanismo de succión la jeringa de Karman de tamaño corriente y cánulas standard tipo Karman números 4 a 6.

TABLA No. 5

CANULA UTILIZADA

\begin{tabular}{ccc}
\hline No. de Cánula & No. de Casos & $\%$ \\
\hline 4 & 26 & 11 \\
5 & 46 & 19 \\
6 & 165 & 70 \\
\hline
\end{tabular}

TABLA No. 6

PESO DEL TEJIDO OBTENIDO

\begin{tabular}{lrr}
\hline & & $\%$ \\
\hline Fragmentos solamente & 70.8 \\
$1-4$ & gramos & 12.3 \\
$5 \quad-9$ & gramos & 10.6 \\
$10-14$ & gramos & 3.8 \\
$15+$ & gramos & 1.7 \\
Sin dato & & 0.8 \\
\hline
\end{tabular}

El porcentaje reiativamente grande de casos con tejido en cantidad apreciable, se debe al número, también proporcionalmente elevado, de procedimientos de tipo diagnóstico-terapéutico. EI gran número de casos en que sólo se obtuvo 'fragmento de tejido', no significa que éste haya sido insuficiente para diagnóstico histopatológico. Por el con trario, la revisión cuidadosa de los infor- 
mes histopatológicos muestra que en sólo 7 casos el material obtenido no permitió hacer un adecuado diagnóstico.

TABLA No. 7

\section{SANGRADO DURANTE}

\section{EL PROCEDIMIENTO}

\begin{tabular}{rrcc}
\hline & & & $\%$ \\
\hline 5 & -4 & $c c$ & 71.3 \\
10 & -14 & $c c$ & 17.8 \\
15 & -19 & $c c$ & 5.9 \\
Sin dato & & 0.8 \\
\hline
\end{tabular}

La cantidad de sangre pérdida por la paciente es calculada por el médico que realiza el procedimiento con base en el número de torundas empapadas $\mathrm{y}$ en su apreciación personal. Por lo tanto, este dato no debe ser considerado exacto; sin embargo, pone de presente el escaso sangrado que se presenta en la gran mayoría de los casos.

\begin{tabular}{lc}
\multicolumn{2}{c}{ TABLA No. 8 } \\
DOLOR \\
\hline Ninguna & $\%$ \\
\hline Leve & 12.3 \\
Moderado & 58.5 \\
Severo & 23.3 \\
Sin Dato & 3.0 \\
\hline
\end{tabular}

Tal como se aprecia en la Tabla 8 , $71 \%$ de las pacientes experimentaron dolor leve o ningún dolor, y sólo 3 de cada 100 refirieron dolor severo:

El muy bajo porcentaje de pacientes que experimentaron algún dolor de consideración, esta directamente relacionado con la administración casi rutinaria de anestesia local (Xylocaína al $1 \%$ ) por vía submucosa en el cuello uterino.

El análisis macroscópico que del tejido obtenido hace habitualmente el médico tratante, permitió identificar correctamente el endometrio en 201 de los 210 casos donde la histopatología confirmó la presencia de este tejido. En 31 casos el médico diagnosticó el tejido como decidua, la cual sólo fue confirmada histológicamente en un caso.

TABLA No. 9

\section{DIAGNOSTICO HISTOPATOLOGICO}

No.
de casos $\%$

Hiperplasia endometrial $\quad 15 \quad 6.4$

Endometrio secretor

$133 \quad 56.4$

Endometrio proliferativo

mal estimulado

$18 \quad 7.6$

Decidua verdadera

10.4

Endometrio proliferativo

$44 \quad 18.7$

Atrofia endometrial

$7 \quad 2.9$

Endometrio secretor con fenómeno Arias Stella

$6 \quad 2.6$

Endometritis

$3 \quad 1.3$

Tejido insuficiente para Dx.

2.9

Sin dato

20.8 


\section{Controles}

$77 \%$ de las pacientes regresaron a control a la institución, encontrándose todas ellas en perfecto estado de salud, $y$, con base en el diagnóstico, el médico prescribió el tratamiento a que hubo lugar. Sólo una paciente presentó, al examen pélvico de control, una masa anexial pequeña y asintomática.

La amplia gama de diagnósticos histopatológicos realizados mediante la utilización de este sistema, nos permite concluir favorablemente sobre su utilidad práctica, que aventaja a los métodos tradicionales en razón de sus características ya anotadas de versatilidad, inocuidad, seguridad, tolerancia y bajo costo.

\section{Ventajas de la aspiración endouterina sobre el raspado}

La utilización del equipo de succión de Karman, con plena observación de los simples cuidados arriba anotados, ofrece ventajas indudables sobre el procedimiento de dilatación y curetaje o raspado uterino. Esta afirmación tiene como base el grado de dilatación cervical necesario que es mucho menor que el que se requiere para permitir el paso de la cureta metálica, y la muy elevada eficacia del sistema de succión que combina, como antes se anotó, la función de aspiración y raspado.

En nuestra experiencia institucional hemos procedido muchas veces a rectificar con la cureta la limpieza de la cavidad, comprobando una y otra vez que las paredes uterinas han quedado completamente limpias después de la succión. En contraste con lo anterior, ocasionalmente, y con carácter experimental, hemos efectuado la operación contraria, esto es, utilizando primera la cureta y luego la succión, después de la cual se han encontrado múltiples fragmentos endometriales todavía presentes en la cavidad uterina.

\section{UTILIZACION DE LA JERINGA DE KARMAN EN GINECOLOGIA}

\section{Resumen}

Históricamente la succión endouterina ha tenido más de un siglo de evolución, llegando a su nivel más avanzado con la aparición del sistema ideado por Harvey Karman basado en jeringas y cánulas de plástico atraumáticas, de alta eficiencia, bajo costo y fácil mantenimiento.

Además, de sus aplicaciones en Obste tricia para la evacuación de restos ovulares retenidos en gestaciones tempranas, en el campo ginecológico la jeringa y cánulas de Karman son de especial utilidad en el diagnóstico y tratamiento de trastornos del ciclo menstrual y en todo tipo de hemorragias uterinas no asociadas a un embarazo, con muy claras ventajas de este sistema sobre el raspado uterino tradicional.

Este trabajo resume los hallazgos y experiencias en 236 pacientes en quienes se utilizó este novedoso sistema de succión endouterina luego de infiltración submucosa del cuello uterino con Xilocaina al $1 \%$ sin epinefrina sin necesidad de hospitalización.

Se utilizaron cánulas de 4 a 6 milímetros de diámetro obteniendose material adecuado para estudio histopatológico en el $97 \%$ de los casos. En 89 de cada 100 la pérdida de sangre fue de $10 \mathrm{ml}$ o menos; $94 \%$ de las pacientes presentaron dolor nulo o moderado.

\section{UTILIZATION OF THE KARMAN SHERINGE IN GYNECOLOGY}

\section{Summary}

Evacuation of the uterine contents has had more than one hundred years of evolution reaching its most advanced stage with the system deviced by Harvey Karman using atraumatic highly eficient and low cost plastic canulae and she ringes. 
Besides its eficient utilization for the evacuation of retained tissue in incomplete abortions of early gestational age, the Karman suction system is extremely valuable in gynecological diagnosis and treatment of menstrual cycle irregularities and hall types of uterine bleedin with great many advantages over traditional dilatation and curetage.

This paper sumarizes the findings in 236 patients in whom this uterine suction method was used in an ambulatory medical center under local anestesia.

Four and six milimeters canulae were used and enough tissue for adequeate histopathologic examination was obtained in $97 \%$ of the cases. In 89 out of each hundred, blood loss was $10 \mathrm{ml}$ or less; $94 \%$ of the patients reported no pain or moderate discomfort.

\section{CITAS BIBLIOGRAFICAS}

1. SIMPSON, J.Y. Clinical lectures on diseases fo women. Blanchard and Lea, Philadelphia: 1863.

2. BYKOV, E. Aspiration of the gravid uterus. Vrachebnoe. Deloe 9:21, 1927.
3. WU, Y.T. and WU H.C. Suction curettage for artificial abortion: Preliminary Report of $\mathbf{3 0 0}$ cases. Chinese Journal of Obstetrics, 6, 26, 1958.

4. LIU, F.A. Comparison of the three methods of artificial abortion: Suction with an injection instrument, electrical suc tion and uterine curettage. Chinese Journal of Obstetrics 12: $18 \mathrm{t}-289,1966$.

(5) BERIC, B.M. and CUPRESANIN. Vacuum aspiration using paracervical block for legal abortions as an outpatient procedure up to the twelvth week of pregnancy. Lancet ii, 619 .

6. KERSLAKE, D. and CASEY, D. Abortion induced by means of u terine aspira tion. American Journal of Obstetrics and Gynecology, New York, 30:35, 1967.

7. KARMAN, $H$. and POTTS, M. Very earley abortion using a syringe as a va cuum source. Lancet 1: 1051-1052. May 13, 1972.

8. NOVAK, E. Suction curette apparatus for endometrial biopsy. Journal of the American Medical Association, 104: $1497,1935$. 